\title{
A DIVULGAÇÃO DO DESEMPENHO DOS ALUNOS DO COLÉGIO MILITAR DE SALVADOR EM OLIMPÍADAS CIENTÍFICAS NACIONAIS COMO FORMA DE REFORÇAR SUA IMAGEM INSTITUCIONAL
}

\author{
AleXANDRE Giacomini ${ }^{1}$, EvERTON LÜDKE $^{2}$ \\ ${ }^{1}$ Colégio Militar de Santa Maria e Universidade Federal de Santa Maria (UFSM) \\ ${ }^{2}$ Universidade Federal de Santa Maria (UFSM) \\ <alexandregiacomini10@gmail.com>, <evertonludke@gmail.com>
}

DOI: 10.21439/conexoes.v11i4.939

\begin{abstract}
Resumo. O presente estudo tem como principal objetivo incrementar a divulgação institucional dos resultados dos alunos obtidos em olimpíadas científicas nacionais de modo a reforçar a imagem do Colégio Militar de Salvador (CMS). Quanto aos aspectos metodológicos, o trabalho pode ser apresentado, quanto ao método e à forma, com viés de um estudo que associou as pesquisas do tipo qualitativa e quantitativa; quanto aos objetivos, como uma pesquisa exploratória e descritiva (ou de campo); e quanto aos procedimentos adotados na coleta de dados, como um estudo de caso. Os instrumentos utilizados na coleta de dados foram: questionário, entrevistas abertas e análise documental. A metodologia de análise dos dados para a parte qualitativa foi a análise textual discursiva, já para parte quantitativa foi a que requereu o uso de recursos e de técnicas estatísticas. A pesquisa foi desenvolvida de abril a agosto de 2015 no CMS, na cidade de Salvador (BA), com a participação de professores e alunos do ensino médio. Os excelentes resultados dos alunos do CMS verificados, nos anos de 2012 a 2014, em olimpíadas científicas nacionais comprovam sua excelência educacional. Quanto aos meios de comunicação utilizados para divulgar os resultados dos alunos do CMS em olimpíadas científicas nacionais, observou-se que eles se limitaram aos informativos e ao site do colégio. Além disso, os meios de divulgação usados atingem quase que exclusivamente pais, professores e alunos.
\end{abstract}

Palavras-chaves: Olimpíadas científicas nacionais. Divulgação institucional. Excelência educacional. Meios de comunicação.

\begin{abstract}
This study aims to increase the institutional dissemination of the results of the students obtained in national scientific Olympiads in order to strengthen the image of the Military School of Salvador (CMS). As for the methodological aspects, the work can be presented as the method and form, to bias a study that associated the research of qualitative and quantitative type; the aims, as an exploratory and descriptive research (or field); and on the procedures adopted in data collection, as a case study. The instruments used in data collection were: questionnaire, open interviews and document analysis. Data analysis methodology for the qualitative part was the discursive textual analysis, while for quantitative part was the one that required the use of resources and statistical techniques. The research was conducted from April to August 2015 in CMS, in Salvador (BA), with the participation of high school teachers and students. The excellent results of CMS students checked in the years 2012-2014, in national scientific Olympiads prove their educational excellence. As for the media used to disseminate the results of the CMS students in national scientific Olympics, it was observed that they were limited to information and to the college's website. In addition, the means of dissemination used almost exclusively reach parents, teachers and students.
\end{abstract}

Keywords: National Scientific Olympics. Institutional promotion. Educational excellence. Media. 


\section{INTRODUÇÃO}

Nos últimos anos, tem havido um crescente interesse na área da educação e do ensino pelo tema da participação em olimpíadas científicas por parte de alunos de escolas, incluindo entre estes os do Colégio Militar de Salvador (CMS). Isso pode ser observado no crescente número de alunos participantes, por exemplo, na Olimpíada Brasileira de Matemática das Escolas Públicas (OBMEP) que passou de aproximadamente 10 milhões de estudantes, em 2005, no seu primeiro ano, para aproximadamente 20 milhões atualmente (OBMEP, 2015).

Tal interesse na participação das olimpíadas científicas, também é evidenciado em estudos de viabilidade para que estas se tornem uma porta de entrada para a universidade de países como a Argentina, por exemplo (CHIROLEU, 2013). Já no Brasil, a OBMEP oferece nesse sentido o Programa de Iniciação Científica e Mestrado (PICME) - trata-se de um programa que oferece aos medalhistas desta olimpíada a possibilidade da realização de mestrado em matemática concomitantemente à sua graduação; as bolsas são oferecidas aos participantes em parceria com o Conselho Nacional de Desenvolvimento Científico e Tecnológico (CNPq) e com a Coordenação de Aperfeiçoamento de Pessoal de Nível Superior (CAPES) (OBMEP, 2015).

A presente pesquisa torna-se relevante, pois o desempenho dos alunos do CMS em olimpíadas científicas nacionais é muito positivo, logo este tem um potencial de divulgação por diferentes meios de comunicação. Essa participação, potencializada pela divulgação, permite ainda, expor a imagem, cultura e valores do colégio.

Além disso, as olimpíadas científicas são excelentes formas de desenvolver as competências dos alunos, bem como de melhorar o rendimento deles nas atividades escolares como nas avaliações das disciplinas. Ademais, as olimpíadas têm um papel motivador no estudo e incentivam os alunos na busca de um melhor desempenho acadêmico.

O mundo olímpico proporciona ao aluno o sentimento de amor ao saber, que se reflete diretamente no comportamento e empolgação dele em sua aula e na escola como um todo. Como benefício adicional, muitas olimpíadas incentivam o trabalho em equipe, reforçando hábitos de estudo, o despertar de vocações científicas e os vínculos de cooperação entre equipes de estudantes e professores (OLIMPÍADA. 2015).

Nesse contexto, emerge o problema de investigação do presente trabalho: como a divulgação do desempenho dos alunos do ensino médio em olimpíadas científicas nacionais pode reforçar a imagem do CMS?

A partir dessa questão, delineiam-se os objetivos do mesmo:

Geral: incrementar a divulgação institucional dos resultados dos alunos obtidos em olimpíadas científicas nacionais de modo a reforçar a imagem do CMS.

Específicos: verificar os resultados dos alunos do CMS em olimpíadas científicas nacionais nos anos 2012 a 2014; verificar quais os meios de comunicação são utilizados pelo CMS na divulgação dos resultados de seus alunos em olimpíadas científicas nacionais, identificando os pontos fortes e as oportunidades de melhorias; propor meios de divulgação dos bons resultados obtidos pelos alunos do CMS em olimpíadas científicas nacionais, através de mídias impressas e de apoio, como forma de reforçar sua imagem institucional.

\section{FUNDAMENTAÇÃO}

Nesta seção serão apresentadas, de forma abrangente e objetiva, as principais teorias evidenciadas para o embasamento da pesquisa, bem como a metodologia empregada no trabalho.

\subsection{As Olimpíadas Científicas}

As Olimpíadas Científicas Nacionais são competições para estudantes do ensino fundamental ou médio, com o objetivo de incentivar e encontrar talentos nas diversas áreas de conhecimento (OLIMPÍADA, 2015).

São exemplos: olimpíadas de matemática, química, astronomia, física, linguística, biologia, robótica, história, entre outras. Algumas consistem de provas teóricas, outras consistem em fazer programas, experimentos e até mesmo debates.

Cada olimpíada tem sua própria inscrição. Em geral, de acordo com os regulamentos das olimpíadas, um professor da escola tem que cadastrá-la no site da competição de interesse. Contudo, algumas competições permitem que os alunos façam provas em universidades ou em outras escolas, caso sua própria escola não possa realizar a inscrição.

As olimpíadas científicas são constituídas, em geral, de três "níveis": estaduais, nacionais e internacionais. Todavia, existem competições regionais também em algumas cidades ou em mais de um estado. Em geral, pode-se participar das competições nacionais sem passar pelas estaduais, porém, para concorrer no nível internacional precisa-se participar das nacionais.

Entre as principais Olimpíadas Científicas Nacionais estão:

Olimpíada Brasileira de Matemática das Escolas Públicas (OBMEP): competição de Matemática, na 
A DIVULGAÇÃO DO DESEMPENHO DOS ALUNOS DO COLÉGIO MILITAR DE SALVADOR EM OLIMPÍADAS CIENTÍFICAS NACIONAIS COMO FORMA DE REFORÇAR SUA IMAGEM INSTITUCIONAL.

qual participam alunos de $6^{\circ}$ ano do Ensino Fundamental ao $3^{\circ}$ ano do Ensino Médio de escolas públicas. As provas são realizadas em duas fases, sendo a primeira realizada na própria escola com 20 questões objetivas. Já a segunda é realizada em locais pré-determinados com questões dissertativas. Os alunos são divididos em níveis para a realização das provas, sendo o nível 1 os alunos do $6^{\circ}$ e $7^{\circ}$ ano, o nível 2 os alunos do $8^{\circ}$ e $9^{\circ}$ ano e o nível 3 os alunos do Ensino Médio. Os alunos são premiados com medalhas de Ouro, Prata, Bronze e também com Menção Honrosa e, além disso, ganham o direito de participar de um curso de iniciação científica na área de matemática por um ano. Um sábado por mês, os alunos têm 6 horas de aulas em locais preestabelecidos e, para complementar, eles participam de um fórum de discussões, no qual devem desenvolver algumas atividades (OBMEP, 2015).

Olimpíada Brasileira de Matemática (OBM): competição de Matemática, na qual participam estudantes do Ensino Fundamental (a partir do $6^{\circ}$ ano), Ensino Médio e Universitário das escolas públicas e privadas de todo o Brasil. As provas são realizadas em três fases, sendo a primeira no primeiro semestre e as outras duas no segundo. Ela convoca os alunos para a seleção de equipes brasileiras de diversas Olimpíadas Internacionais de Matemática (OBM, 2015).

Olimpíada Brasileira de Física (OBF): competição de Física na qual participam alunos do $8^{\circ}$ ano do Ensino Fundamental ao $3^{\circ}$ ano do Ensino Médio de escolas públicas e privadas. As provas são realizadas em três fases, todas no segundo semestre de cada ano. Ela convoca os melhores medalhistas para a seleção das equipes brasileiras que representarão o Brasil nas Olimpíadas Internacionais de Física (OBF, 2015).

Olimpíada Brasileira de Física das Escolas Públicas (OBFEP): programa permanente da Sociedade Brasileira de Física (SBF) que aconteceu a primeira vez em 2010 com um projeto piloto para os estados da Bahia, Goiás, Piauí e São Paulo, atualmente será realizado a nível nacional. A competição é composta de duas fases e alunos do $9^{\circ}$ ano (Ensino Fundamental) ao $3^{\circ}$ ano do Ensino Médio de escolas municipais, estaduais e federais podem participar.

Olimpíada Brasileira de Química Júnior (OBQ Jr.): competição de Química para alunos do $8^{\circ}$ e $9^{\circ}$ ano, realizada em duas fases no segundo semestre do ano. A prova cobra o assunto do Ensino Médio para alunos do Fundamental. Ela classifica para a OBQ no ano seguinte.

Olimpíada Brasileira de Química (OBQ): competição de Química para alunos do Ensino Médio, realizada com 6 fases, sendo duas delas realizadas por outras competições, como a Olimpíada Brasileira de Química Júnior (OBQJr) ou a Olimpíada Estadual de Química, tendo sido premiada em alguma destas competições anteriormente à OBQ de um determinado ano. E, por ela, poderá chegar-se às Olimpíadas Internacionais de Química (PNOQ, 2015).

Olimpíada Brasileira de Astronomia e Astronáutica (OBA): competição de Astronomia e Astronáutica para alunos do $1^{\circ}$ ano do Ensino Fundamental ao $3^{\circ}$ ano do Ensino Médio, embora estas matérias não sejam cobradas diretamente na prova, podendo ter conteúdos de Lógica, Física, Geografia ou Matemática. Possui fase única, realizada no $1^{\circ}$ semestre, e os alunos são divididos em 4 níveis. Essa competição classifica para a seletiva dos estudantes que nos representarão nas Olimpíadas Internacionais de Astronomia (OBA, 2015).

Olimpíada Nacional em História do Brasil (ONHB): competição de História do Brasil que começou em 2009 e é elaborada pelo Departamento de História da Universidade Estadual de Campinas (UNICAMP). Possui um formato original, pois suas provas são feitas em equipe e pela internet. Ao longo de várias fases, os alunos têm tempo de pesquisar e perguntar a professores sobre as questões, com exceção da Fase Final, que é uma prova presencial, na qual o professor representante da equipe não participa.

Olimpíada Brasileira de Biologia (OBB): prova de Biologia realizada para alunos do Ensino Médio. Cobra as matérias do Ensino Médio e conteúdos extras (normalmente visto em materiais de introdução do Ensino Superior, ou estudando as provas passadas). Os vencedores desta competição representam o Brasil na Olimpíada Internacional de Biologia (IBO) e na Iberoamericana de Biologia (OBB, 2015).

Olimpíada Brasileira de Informática (OBI): trata-se de uma Olimpíada de Lógica nos níveis Iniciação 1 (até o $7^{\circ}$ ano) e Iniciação 2 (até o $9^{\circ}$ ano) e de programação computacional para os níveis Programação Júnior (até o $9^{\circ}$ ano), Programação 1 (até o $2^{\circ}$ colegial) e Programação 2 (até o $1^{\circ}$ ano da faculdade). Os vencedores da P2 participam de uma seleção para representar o Brasil na Olimpíada Internacional de Informática (OBI, 2015).

Olimpíada Brasileira de Robótica (OBR): competição de robótica apoiada pelo $\mathrm{CNPq}$, subdividida em duas modalidades teóricas (Teórica e Duathlon) e uma prática. Na modalidade Teórica participam alunos de $1^{\mathrm{a}}$ a $8^{\mathrm{a}}$ série $\left(6^{\circ}\right.$ ao $9^{\circ}$ ano). Na modalidade Duathlon participam Alunos do Ensino Médio que nunca tenham participado da construção de algum robô. Na modalidade Prática, todos podem participar (OBR, 2015).

Olimpíada Brasileira de Geografia (OBG): competição de geografia para estudantes das escolas públicas 
A DIVULGAÇÃO DO DESEMPENHO DOS ALUNOS DO COLÉGIO MILITAR DE SALVADOR EM OLIMPÍADAS CIENTÍFICAS NACIONAIS COMO FORMA DE REFORÇAR SUA IMAGEM INSTITUCIONAL.

e particulares do Brasil, desde o $9^{\circ}$ ano do Ensino Fundamental até o $3^{\circ}$ ano do Ensino Médio. Os estudantes participantes da olimpíada deverão demonstrar a sua capacidade de análise e interpretação dos fenômenos geográficos de modo integrado, rompendo com o dualismo geografia física x geografia humana que deve estar expressa nas metodologias de ensino e aprendizagem contidas na formação desses estudantes (OBG, 2015).

\subsection{O Sistema Colégio Militar do Brasil e o Colégio Militar de Salvador}

Os Colégios Militares são Organizações Militares (OM) que funcionam como estabelecimentos de ensino de educação básica que têm as seguintes finalidades:

\footnotetext{
- Prover ao ensino assistencial para os dependentes de militares do Exército e de outras Forças; - Ministrar o ensino fundamental e médio a alunos de ambos os sexos; - Atender, também, o ensino fundamental e médio para os filhos de civis; - Desenvolver nos alunos o sentimento de amor à Pátria e o culto de suas tradições; Assegurar preparo intelectual necessário à continuidade dos estudos em níveis superiores; - Aprimorar as qualidades físicas do educando; - Desenvolver sadia mentalidade de disciplina consciente; - Desenvolver a capacidade de pensar do educando; - Despertar vocações para a carreira militar no Exército; - Preparar candidatos para o ingresso na Escola Preparatória de Cadetes do Exército (EsPCEx) (CMPA. 2015).
}

Esses colégios integram o Sistema Colégio Militar do Brasil (SCMB) e são subordinados diretamente à Diretoria de Educação Preparatória e Assistencial (DEPA).

A educação preparatória dos colégios militares orienta o ensino para a vida, a busca ética da felicidade e a realização pessoal. O ensino preparatório deve habilitar todos os alunos ao prosseguimento dos estudos, seja pelo despertar das vocações militares, seja pela preparação aos processos seletivos à Educação Superior.

Já a educação assistencial remete à gênese e à justificativa do próprio Sistema Colégio Militar do Brasil (SCMB): a busca do equacionamento das vicissitudes inerentes à profissão militar, das dificuldades impostas à família castrense que impactam a moral da tropa.

O SCMB preocupa-se em formar jovens ativos e criativos, autônomos e autores, providos de competências, habilidades, atitudes, valores e experiências cultuadas pelo Exército Brasileiro, ou seja, indivíduos mais responsáveis, atuantes e transformadores. Além disso, o SCMB presta assistência aos filhos de militares proporcionando um ensino de qualidade com baixo custo.
Nesse contexto, o Colégio Militar de Salvador é um dos integrantes do SCMB. Iniciou suas atividades em 05 de Abril de 1957, sendo comandado pelo Coronel Uchôa. O Colégio veio para o bairro da Pituba em 02 de Julho de 1961 e foi desativado em 1989, voltando a funcionar novamente em 1993, graças a um convênio firmado entre Exército Brasileiro e o Governo do Estado da Bahia. Atualmente o CMS oferece aos alunos do Ensino Fundamental ( $6^{\circ}$ ao $9^{\circ}$ ano) e de Ensino Médio ( $1^{\circ}$ ao $3^{\circ}$ ano) educação de alta qualidade (ESFCEX, 2015, CMPA, 2015).

\subsection{Divulgação dos resultados: imagem institucio- nal e propaganda}

Tomando-se por base o histórico de publicações da Seção de Comunicação Social do Colégio Militar de Salvador, é possível verificar que, até o momento, os meios de comunicação utilizados para divulgar os resultados de seus alunos em olimpíadas científicas nacionais, limitaram-se aos informativos e ao site do colégio. Além disso, os meios de divulgação usados atingem, quase que exclusivamente, pais, professores e alunos. Do exposto acima, fica evidente que os poucos veículos usados e o público restrito diminuem o impacto da divulgação.

Com a motivação de que os meios de divulgação empregados são quase limitados ao público interno, justifica-se o objetivo da presente pesquisa em reforçar a imagem institucional por meio de uma maior divulgação dos resultados dos alunos em olimpíadas científicas nacionais.

Nesse sentido, entende-se que a Seção de Comunicação Social do CMS pode lançar mão de outros meios para ampliar a divulgação dos resultados; meios estes embasados no Manual de Campanha de Comunicação Social do Exército (C 45-1), mais particularmente no que se versa sobre Mídias de Apoio tais como o uso de Outdoors e folhetos, justificados pelo seu baixo custo e pela sua grande profundidade de ação. Sobre as Mídias de Apoio do Manual de Campanha de Comunicação Social do Exército, tem-se que:

\footnotetext{
São meios complementares destinados a reforçar a veiculação feita pela mídia principal, de acordo com o planejamento de "marketing" institucional. Os tipos são variados e seu emprego é em função da oportunidade e da criatividade. Podem ser listados: a. "Outdoors" O outdoor é uma das mais utilizadas formas de propaganda ao ar livre. São painéis, normalmente com três metros de altura por nove de largura, para serem vistos de longe aproximadamente 100 metros - tendo como tempo médio de leitura seis segundos. As mensagens devem ser
} 
A DIVULGAÇÃO DO DESEMPENHO DOS ALUNOS DO COLÉGIO MILITAR DE SALVADOR EM OLIMPÍADAS CIENTÍFICAS NACIONAIS COMO FORMA DE REFORÇAR SUA IMAGEM INSTITUCIONAL.

curtas e apoiadas por ilustrações ou fotografias. É um excelente veículo para fixação da imagem institucional. [...]

f. Volantes, folhetos e folders (panfletos) Mídias dirigidas para distribuição de mão em mão ou por mala direta. Por esse motivo, deve ter um apelo visual bastante atrativo e não deve ser um produto muito volumoso (BRASIL 2009).

\subsection{Por que é importante reforçar a divulgação ins- titucional e manter a comunicação interna?}

A divulgação institucional é assim vista segundo o viés do exército:

[...] atividade que visa a produzir e a disseminar a imagem do Exército. [...] utiliza-se dos veículos de comunicação e dos canais de distribuição para levar os seus produtos aos públicos-alvos. A divulgação das atividades desenvolvidas pelo Exército é feita por intermédio das mais variadas mensagens institucionais, que, por sua vez, estão inseridas nos produtos de mídia impressa e eletrônica (BRASIL 2009 p. 11)

Já a comunicação interna é um agente de suma relevância para os gestores, para as organizações e para as pessoas. Nesse sentido, Pasqualini (2006) ressalta que a comunicação interna tem como objetivo transmitir aos seus funcionários os acontecimentos, partilhar um sistema de valores, de procedimentos e de rituais próprios da organização, e acima de tudo firmar uma imagem positiva em suas mentes.

Nesse escopo, a comunicação interna contribui para o desenvolvimento e manutenção de um clima positivo, propício ao cumprimento das metas estratégicas e ao crescimento continuado das atividades da organização (TORQUATO, 2002).

Corroborando nessa linha, para Corrado (1994), a comunicação interna aumenta os esforços para que todos criem identidade com a empresa, gerando maior comprometimento e satisfação dos profissionais envolvidos.

Diante desses conceitos, depreende-se que a divulgação dos resultados em olimpíadas científicas melhora o relacionamento entre a instituição (CMS) e seu público interno reforçando a imagem institucional.

\subsection{Relações Públicas e Comunicação Social: o que o CMS tem a ganhar com o reforço de sua imagem na opinião pública?}

Para Kunsch (2009, p. 115), as relações públicas têm como objeto de estudo todas as organizações e seus públicos. Esse processo mediador só ocorre por meio da comunicação externa, contexto no qual a comunicação organizacional fornece subsídios teóricos para fundamentar a administração dos relacionamentos sobre organizações e públicos.
Para a mesma autora (2009, p. 19), ao se referenciar ao objetivo da comunicação organizacional, diz:

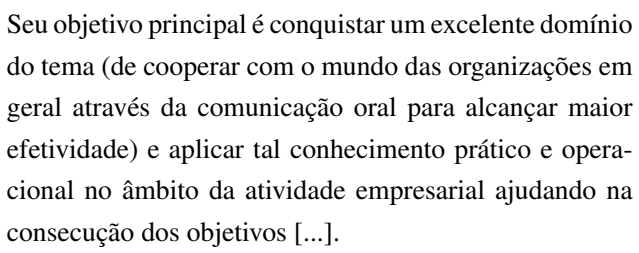

Diante deste particular, entende-se que Colégio Militar de Salvador precisa estender e reforçar seu relacionamento com o público externo, e que tal relacionamento pode divulgar sua imagem tal como acontece nas relações mercadológicas.

\section{METODOLOGIA}

A presente pesquisa, quanto ao método e à forma apresentada, tem viés, de acordo com Zanella (2009), de um estudo que associou as pesquisas do tipo qualitativa e quantitativa, pois se preocupou com o processo, com a descrição e compreensão dos fenômenos a partir do ponto de vista do grupo pesquisado (professores e alunos do ensino médio do CMS), bem como procurou traduzir em números as opiniões e as informações deste grupo para, posteriormente, classificá-las e analisá-las.

Quanto aos objetivos, a pesquisa pode ser caracterizada, de acordo com GIL (2007), como uma pesquisa exploratória, uma vez que visa conhecer a literatura da área e descritiva (ou de campo), pois verifica e descreve os resultados dos alunos do CMS em olimpíadas científicas nacionais nos anos 2012 a 2014, bem como os meios de comunicação que são utilizados pelo mesmo na divulgação dos resultados de seus alunos nessas olimpíadas.

Quanto aos procedimentos adotados na coleta de dados, o estudo tem viés de uma pesquisa do tipo estudo de caso (CHIZZOTTI, 1995), pois ele visa à descoberta, à interpretação no contexto e retrata em profundidade a realidade do CMS.

Os instrumentos utilizados na coleta de dados foram: questionário (APÊNDICE), entrevistas abertas e análise documental.

A presente pesquisa utilizou como metodologia de análise dos dados para a parte qualitativa, a análise textual discursiva (MORAES; GALIAZZI, 2007), uma vez que procurou-se trabalhar com materiais textuais escritos. Já a metodologia de análise de dados utilizada para a parte quantitativa foi a que requereu o uso de recursos e de técnicas estatísticas.

Esta pesquisa foi desenvolvida de abril a agosto de 2015 no CMS, na cidade de Salvador (BA), com a participação de professores e alunos do ensino médio. 
A DIVULGAÇÃO DO DESEMPENHO DOS ALUNOS DO COLÉGIO MILITAR DE SALVADOR EM OLIMPÍADAS CIENTÍFICAS NACIONAIS COMO FORMA DE REFORÇAR SUA IMAGEM INSTITUCIONAL.

A amostra foi constituída pelos principais professores que estavam à frente da organização das olimpíadas científicas e por 95 alunos do ensino médio.

\section{RESUltados e conclusões}

Esta seção apresenta e discute os resultados obtidos no trabalho, bem como aponta conclusões do mesmo.

\subsection{Resultados da análise documental e entrevis- tas}

Os resultados abaixo foram coletados a partir de entrevistas realizadas com professores e análise documental obtida através de meios digitais, bem como por meio do colégio.

O CMS apresenta uma boa participação nas olimpíadas científicas nacionais, destacando-se em muitas delas. Dentre as principais olimpíadas que o colégio participa temos: a Olimpíada Brasileira de Matemática das Escolas Públicas (OBMEP), a Olimpíada Brasileira de Física (OBF), a Olimpíada Brasileira de Geografia (OBG), a Olimpíada Brasileira de Astronomia (OBA), a Olimpíada Brasileira de Biologia (OBB), Olimpíada Brasileira de Matemática (OBM) e Olimpíada Brasileira de Química Júnior (OBQJR).

\subsection{Resultados do ano de 2012}

No ano de 2012, o CMS obteve medalhas e menções honrosas nas seguintes competições: OBMEP, OBM, OBF, OBFEP e OBQJR. Seguem abaixo na Tabela 1 as premiações que o colégio obteve nas olimpíadas:

Além dos resultados acima divulgados, vale ressaltar o desempenho dos alunos do colégio no concurso Soletrando de 2012. O concurso Soletrando acontece desde 2007 no programa Caldeirão do Huck, na Rede Globo e tem como objetivo incentivar o estudo da língua portuguesa. Nesta competição é apresentado aos participantes palavras da nossa língua que devem ser soletradas de forma correta e à medida que o participante vai acertando as palavras vão elevando o seu grau de dificuldade. Os três finalistas do concurso Soletrando, em 22 de setembro de 2012, eram todos de Colégios Militares que integram o SCMB: a $1^{\text {a }}$ colocada era do Colégio Militar de Porto Alegre (CMPA), o $2^{\circ}$ colocado era aluno do CMS e o $3^{\circ}$ colocado era do Colégio Militar de Recife (CMR).

\subsection{Resultados do ano de 2013}

Já no ano de 2013, o CMS ampliou suas participações em olimpíadas científicas nacionais e teve seus alunos premiados conforme a Tabela 2 abaixo:
Tabela 1: Premiação das Olimpíadas no ano de 2012

\begin{tabular}{|c|c|}
\hline $\begin{array}{c}\text { Olimpíadas } \\
\text { Científicas } \\
\text { Nacionais }\end{array}$ & Premiação do CMS \\
\hline OBF & 01 medalha de ouro \\
(Premiação Regional) & 01 medalha de prata \\
& 02 menções honrosas \\
\hline OBF & 03 medalhas de ouro \\
(Premiação Nacional) & 03 medalhas de prata \\
& 02 menções honrosas \\
\hline & 35 medalhas de ouro \\
OBFEP & 16 medalhas de prata \\
& 12 medalhas de bronze \\
\hline & 07 medalhas de ouro \\
OBM & 04 medalhas de prata \\
(Etapa Regional) & 12 medalhas de bronze \\
& 11 menções honrosas \\
\hline & 01 medalha de ouro \\
OBMEP & 01 medalha de prata \\
& 12 menções honrosas \\
\hline OBQJR & 01 medalha de ouro \\
& 01 medalha de bronze \\
& 01 menção honrosa \\
\hline Fonte: Elaborado pelos autores, 2015.
\end{tabular}

Destaque para um aluno que foi premiado nacionalmente com uma medalha de ouro na OBF e, com isso, pôde participar da seletiva para a Olimpíada Internacional de Física. Dessa maneira, tanto o CMS como um de seus professores de Física também foram premiados pelo bom desempenho dos alunos na OBFEP.

\subsection{Resultados do ano de 2014}

O CMS em 2014 também participou de competições olímpicas e podemos destacar as premiações obtidas conforme a Tabela 3 abaixo:

Novamente vale salientar que o CMS e um de seus professores de Física, foram premiados pela OBFEP, devido ao grande número de medalhas conquistadas pelos seus alunos.

Portanto, os resultados dos alunos do CMS verificados, nos anos de 2012 a 2014, comprovam sua excelência educacional.

Além disso, em entrevista com os professores encarregados das disciplinas de Matemática, Física e Biologia, foi possível observar os esforços dos mesmos para que os alunos participem das olimpíadas científicas nacionais. Verificou-se, ainda, que mesmo não havendo carga horária curricular disponível para treinamento dos alunos nessas olimpíadas, os docentes as 
Tabela 2: Premiação das Olimpíadas no ano de 2013

\begin{tabular}{|c|c|}
\hline $\begin{array}{c}\text { Olimpíadas } \\
\text { Científicas } \\
\text { Nacionais }\end{array}$ & Premiação do CMS \\
\hline OBF & 03 medalha de ouro \\
(Premiação Estadual) & 01 medalha de prata \\
& 01 medales honrosas de prata \\
\hline OBF & 01 medalhas de bronze \\
(Premiação Nacional) & 01 menções honrosa \\
\hline OBFEP & 01 medalhas de ouro \\
(Premiação Nacional) & 01 medalhas de prata \\
& 05 medalhas de bronze \\
\hline OBFEP & 05 medalhas de ouro \\
OB medalhas de prata \\
(Premiação Estadual) & 04 medalhas de bronze \\
\hline OBM & 01 menções honrosas \\
\hline (Etapa Nacional) & 01 medalha de ouro \\
& 03 medalha de prata \\
& 04 menção bronze \\
OBMEP & 14 menções honrosas \\
\hline OBG & 02 medalhas de bronze \\
\hline OBonte: Elaborado pelos autores, 2015 & 01 medalha de ouro \\
& 05 medalhas de prata \\
& 08 medalhas de bronze \\
\hline OBA & 03 menc̃os honrosas \\
\hline &
\end{tabular}

Tabela 3: Premiação das Olimpíadas no ano de 2014

\begin{tabular}{|c|c|}
\hline $\begin{array}{l}\text { Olimpíadas } \\
\text { Científicas } \\
\text { Nacionais }\end{array}$ & Premiação do CMS \\
\hline $\begin{array}{c}\text { OBF } \\
\text { (Premiação Regional) }\end{array}$ & $\begin{array}{l}03 \text { medalha de ouro } \\
04 \text { medalhas de prata } \\
03 \text { medalhas bronze } \\
01 \text { menções honrosas }\end{array}$ \\
\hline $\begin{array}{c}\text { OBFEP } \\
\text { (Premiação Estadual) }\end{array}$ & $\begin{array}{l}05 \text { medalhas de ouro } \\
06 \text { medalhas de prata } \\
02 \text { menções bronze }\end{array}$ \\
\hline $\begin{array}{c}\text { OBFEP } \\
\text { (Premiação Nacional) }\end{array}$ & $\begin{array}{l}03 \text { medalhas de ouro } \\
02 \text { medalhas de prata } \\
04 \text { medalhas de ouro }\end{array}$ \\
\hline $\begin{array}{c}\text { OBM } \\
\text { (Etapa Regional) }\end{array}$ & $\begin{array}{c}01 \text { medalha de ouro } \\
02 \text { medalhas de bronze }\end{array}$ \\
\hline OBMEP & $\begin{array}{l}03 \text { medalhas de prata } \\
04 \text { medalhas de bronze } \\
18 \text { menções honrosas }\end{array}$ \\
\hline OBQ & 01 medalha de ouro \\
\hline OBA & $\begin{array}{l}03 \text { medalhas de ouro } \\
02 \text { medalhas de prata } \\
05 \text { medalhas e bronze }\end{array}$ \\
\hline $\mathrm{OBNH}$ & 03 medalhas de prata \\
\hline $\mathrm{OBB}$ & $\begin{array}{l}1^{\circ} \text { colocação } \\
8^{\circ} \text { colocação }\end{array}$ \\
\hline
\end{tabular}




\section{A DIVULGAÇÃO DO DESEMPENHO DOS ALUNOS DO COLÉGIO MILITAR DE SALVADOR EM OLIMPÍADAS CIENTÍFICAS}

NACIONAIS COMO FORMA DE REFORÇAR SUA IMAGEM INSTITUCIONAL.

divulgam e inscrevem os interessados, mediante aquiescência de seus responsáveis.

\subsection{Resultados do questionário}

A base total de dados coletados foi de 95 questionários respondidos pelos alunos do ensino médio, entre eles, 30 foram respondidos pelos alunos do $1^{\circ}$ ano, 29 pelos do $2^{\circ}$ ano e 36 pelo $3^{\circ}$ ano. Desse universo, $34,7 \%$ eram do sexo feminino e $65,3 \%$ eram do sexo masculino.

A média de idade em cada ano foi respectivamente: 15,4 anos no $1^{\circ}, 16,2$ anos no $2^{\circ}$ e 17 anos no $3^{\circ}$.

Com relação às disciplinas que os alunos mais têm aptidão ou gostam mais, obtiveram-se os seguintes resultados explanadosno da Figura 1 abaixo:

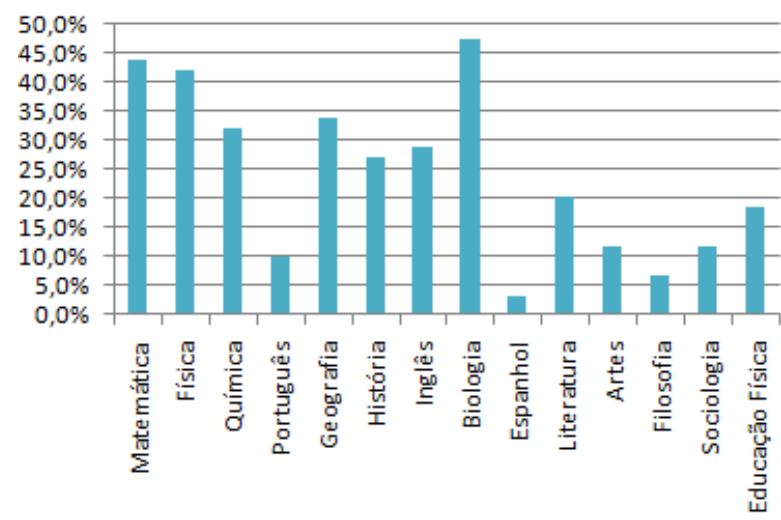

Figura 1: Disciplinas que os alunos mais tem aptidão ou mais gostam Fonte: Elaborado pelos autores, 2015

Já quanto às olimpíadas científicas que os alunos mais participaram, obtiveram-se os seguintes resultados explanados na Figura 2 abaixo:

Analisando-se os resultados dos dois gráficos supramencionados, observa-se que existe, de maneira geral, uma correlação entre as disciplinas que os alunos mais têm aptidão ou gostam mais com as olimpíadas científicas que eles mais participaram. Por exemplo, observase na Figura 11, como destaque, um maior percentual de preferência para as disciplinas de matemática, física e biologia; já na Figura 2, isso se repete, ou seja, há uma maior participação por parte dos alunos nas olimpíadas científicas de matemática (OBM e OBMEP), física (OBF) e biologia (OBB). Depreende-se, portanto, desses resultados que as olimpíadas científicas que os alunos mais procuram participar estão diretamente ligadas às disciplinas que eles têm mais preferência.

Quanto ao questionamento sobre como os alunos ficaram sabendo da olimpíada científica da qual participaram, obtiveram-se os seguintes resultados explanados

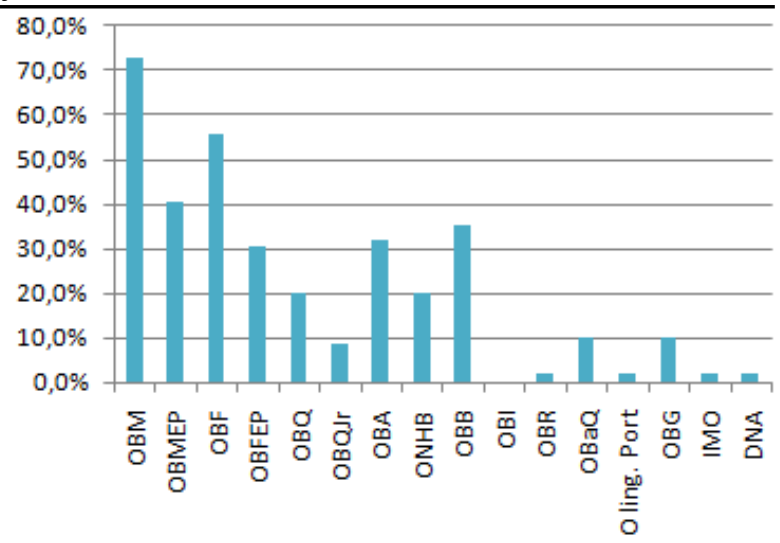

Figura 2: Olímpiadas Científicas que os alunos participaram Fonte: Elaborado pelos autores, 2015

na Figura 3 abaixo:

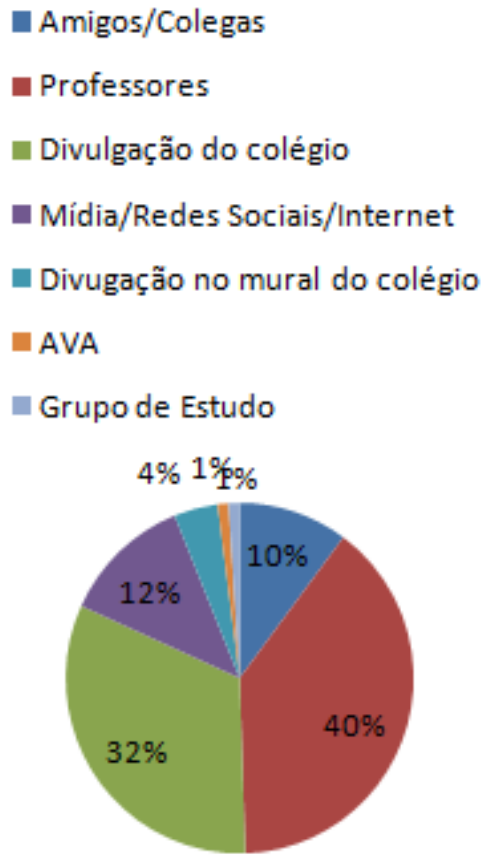

Figura 3: Formas que os alunos ficaram sabendo das olimpíadas científicas

Fonte: Elaborado pelos autores, 2015

Observa-se a partir da Figura 3 que a maioria dos alunos ficou sabendo da olimpíada científica da qual participou por meio de professores do colégio e da divulgação do mesmo.

Outra questão relevante a ser analisada foi: "Você 
A DIVULGAÇÃO DO DESEMPENHO DOS ALUNOS DO COLÉGIO MILITAR DE SALVADOR EM OLIMPÍADAS CIENTÍFICAS NACIONAIS COMO FORMA DE REFORÇAR SUA IMAGEM INSTITUCIONAL.

acredita que sua participação em olimpíadas científicas melhorou a imagem de sua escola? De que forma?".

Abaixo são apresentados os resultados dessa questão sob a forma da Figura 4

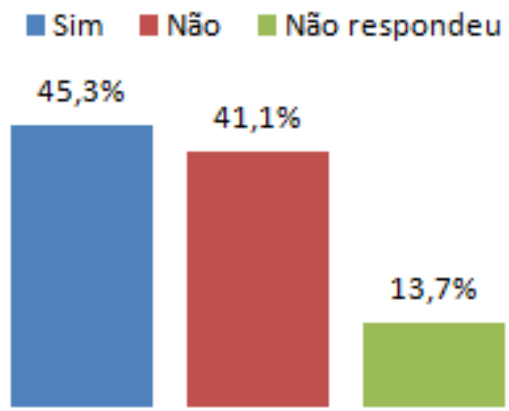

Figura 4: Se a participação em olimpíadas científicas reforça a imagem do CMS

Fonte: Elaborado pelos autores, 2015

Observa-se a partir da Figura 4 que a maioria dos alunos $(45,3 \%)$ acredita que sua participação em olimpíadas científicas reforçou a imagem do CMS. Isso pode ser comprovado por alguns depoimentos a seguir, representativos do conjunto de alunos:

\footnotetext{
Sim, uma vez que vários alunos obtiveram medalhas, representaram e exaltaram o nome do colégio nessas competições. (Aluno A).

Sim, as olimpíadas fortalecem a imagem do colégio, pois é através delas que o colégio pode mostrar como possui um ensino diferencial na formação dos alunos. (Aluno B).

Sim, pois isso acaba valorizando e divulgando o ensino do colégio. (Aluno $\mathrm{C}$ ).

Sim, pois o colégio ganha maior prestígio e visibilidade pelo público em geral. (Aluno D)

Sim, pois traz gratificação através das propagandas de divulgação. (Aluno E).

Sim, pois as pessoas têm uma visão da grandeza e excelência do CMS. (Aluno F).
}

Já para um número também expressivo de alunos $(41,1 \%)$, observou-se que a participação em olimpíadas científicas não melhorou a imagem do CMS. Esses resultados são apontados principalmente pela pouca divulgação em meios internos e externos, conforme destacada na fala de um aluno, representativa do conjunto:

O CMS não divulga no meio externo as conquistas de seus alunos. O máximo que faz é anunciar no AVA e em cerimônias internas, não há divulgação no site nem em veículos externos. (Aluno $\mathrm{X}$ ).
É nesse contexto que mais umavez ressalta-se o objetivo da presente pesquisa em reforçar a imagem institucional por meio de uma maior divulgação dos resultados dos alunos em olimpíadas científicas nacionais em Mídias de Apoio tais como o uso de Outdoors e folhetos, justificadas pelo seu baixo custo e pela sua grande profundidade de ação.

\section{REFERÊNCIAS}

BRASIL. Ministério da Defesa. Exército Brasileiro. Estado Maior do Exército. Manual de Campanha C 45-1: Comunicação Social. $1^{\circ}$ Ed, 2009.

CHIROLEU, A. Políticas públicas de Educación Superior en Amércia Latina: ¿ Democratización o expansión de las oportunidades enelnivel superior? Espacio Abierto, v. 22, n. 2, p. 279-304, 2013. Universidad de Zulia - Maracaibo - Venezuaela.

CHIZZOTTI, A. Pesquisa em ciências humanas e sociais. : 2. ed. São Paulo: Cortez, 1995.

CMPA. 2015. Disponível em: <http://www.cmpa. ensino.eb.br/index.php/colegio/o-colegio $>$, Acesso em: 24 jul 2015.

CORRADO, F. M. A Força da Comunicação. : São Paulo: Makron books, 1994.

ESFCEX. 2015. Disponível em: <http://www.esfcex. ensino.eb.br> Acesso em: 24 jul 2015.

GIL, A. C. Métodos e técnicas de pesquisa social. : 5. Ed. São Paulo: Atlas, 2007.

KUNSCH, M. M. K. Relações públicas e comunicação organizacional. : São Caetano do Sul - SP, Ed. Difusão, 2009

MORAES, R.; GALIAZZI, M. C. Análise Textual Discursiva. : Ijuí: Ed. Unijuí, 2007. 224 p.

OBA. 2015. Disponível em: <http://www.oba.org.br> Acesso em: 01 maio 2015.

OBB. 2015. Disponível em: <http://obb.anbiojovem. org.br> Acesso em: 01 maio 2015.

OBF. 2015. Disponível em: <http://www.obf.org.br> Acesso em: 01 maio 2015.

OBG. 2015. Disponível em: <http://www.obg.net.br> Acesso em: 01 maio 2015.

OBI. 2015. Disponível em: <http://www.obi.org.br> Acesso em: 01 maio 2015. 
OBM. 2015. Disponível em: <http://www.obm.org.

br> Acesso em: 01 maio 2015.

OBMEP. 2015. Disponível em: <http://www.obmep.

org.br>. Acesso em: 01 maio 2015.

OBR. 2015. Disponível em: <http://www.obr.org.br>

Acesso em: 01 maio 2015.

OLIMPÍADA, C. 2015. Disponível em:

$<$ http://www.olimpiadascientificas.com $>$ Acesso em: 24 jul 2015.

PASQUALINI, J. A. A Integração da Comunicação

Interna: o papel da comunicação interna atual.

Monografia apresentada ao Departamento de Relações

Públicas, Propaganda e Turismo da Universidade de

São Paulo para obtenção do título de especialista,

orientada por Arlindo Ornellas Figueira Neto, São

Paulo, 2006.

PNOQ. 2015. Disponível em: <http://www.obquimica. org> Acesso em: 01 maio 2015.

TORQUATO, G. Tratado de comunicação

organizacional e política. São Paulo: Pioneira

Thomson Learning, 2002.

ZANELLA, L. C. H. Metodologia de estudo e de pesquisa em administração. Florianópolis:

Departamento de Ciências da Administração/UFSC,

[Brasília]: CAPES: UAB, p. 164, 2009. 
A DIVULGAÇÃO DO DESEMPENHO DOS ALUNOS DO COLÉGIO MILITAR DE SALVADOR EM OLIMPÍADAS CIENTÍFICAS NACIONAIS COMO FORMA DE REFORÇAR SUA IMAGEM INSTITUCIONAL.

APÊNDICE - QUESTIONÁRIO PARA ALUNOS

1) Idade:

2) Turma:

3) Sexo: ( ) Masculino ( ) Feminino

4) Em que ano do Ensino Médio você está? ( ) $1^{\circ}$ Ano ( ) $2^{\circ}$ Ano （ ) $3^{\circ}$ Ano

5) Qual disciplina escolar você tem mais aptidão ou gosta mais?
( ) Matemática ( ) Fisica
( ) Química ( ) Português
( ) Geografia ( ) História
( ) Inglês
( ) Biologia
( ) Espanhol
( ) Literatura
( ) Artes
( ) Filosofia
( ) Sociologia
( ) Educação Física

6) Você já participou de alguma Olimpiada Cientifica [ex: Olimpiada Brasileira de Matemática (OBM), Olimpiada Brasileira de Física (OBF), Olimpiada Brasileira de Química $(\mathrm{OBQ})$, Olimpiada Brasileira de Astronomia e Astronáutica (OBA), Olimpíada Nacional em História do Brasil (ONHB), Olimpíada Brasileira de Biologia (OBB), Olimpíada Brasileira de Informática (OBI), Olimpíada Brasileira de Robótica (OBR), etc]?

( ) $\operatorname{Sim}($ ) Não

Qual(is)? (Use as abreviações se quiser)

7) Você já ganhou medalhas ou menção honrosa em alguma Olimpiada Cientifica?

( ) $\operatorname{Sim}$ ( ) Não

Caso a resposta da pergunta anterior seja positiva, cite as Olimpiadas que teve premiação, qual foi a premiação e o ano em que participou?

\begin{tabular}{|l|l|l|}
\hline $\begin{array}{l}\text { Olimpiada } \\
\text { Cientifica }\end{array}$ & Medalha & Ano \\
\hline & & \\
\hline & & \\
\hline & & \\
\hline & & \\
\hline & & \\
\hline & & \\
\hline & & \\
\hline
\end{tabular}

8) De que forma você ficou sabendo da olimpiada cientifica da qual participou? Essa forma contribuiu para seu maior interesse na participação da mesma? Por quê?

9) Caso você tenha participado de alguma olimpíada cientifica, diga como foi sua preparação?

10) Você acredita que sua participação em olimpiadas cientificas melhorou seu rendimento em sala de aula? De que forma?

11) Você acredita que sua participação em olimpiadas cientificas melhorou a imagem de sua escola? De que forma? 